\begin{tabular}{|c|c|c|}
\hline \multirow{3}{*}{$\begin{array}{r}\text { Case Reports in } \\
\text { Gastroenterology }\end{array}$} & \multirow{2}{*}{\multicolumn{2}{|c|}{ Case Rep Gastroenterol 2016;10:332-337 }} \\
\hline & & \\
\hline & $\begin{array}{l}\text { DOI: 10.1159/000446575 } \\
\text { Publisned online: June 27, } 2016\end{array}$ & $\begin{array}{l}\text { (c) } 2016 \text { The Author(s) } \\
\text { Published by S. Karger AG, Basel } \\
\text { www.karger.com/crg }\end{array}$ \\
\hline & $\begin{array}{l}\text { This article is licensed under } \mathrm{t} \\
\text { International License (CC BY-NC } \\
\text { Usage and distribution for comm }\end{array}$ & $\begin{array}{l}\text { nons Attribution-NonCommercial } 4.0 \\
\text { ger.com/Services/OpenAccessLicense). } \\
\text { juires written permission. }\end{array}$ \\
\hline
\end{tabular}

\title{
Crystal-Associated Colitis with Ulceration Leading to Hematochezia and Abdominal Pain
}

\author{
Meeta Desai ${ }^{a} \quad$ Aaron Reiprich $^{b} \quad$ Nancy Khov $^{c}$ Zhaohai Yang ${ }^{d}$ \\ Abraham Mathew ${ }^{c}$ John Levenick ${ }^{c}$ \\ ${ }^{a}$ Department of Internal Medicine, Penn State Milton S. Hershey Medical Center,

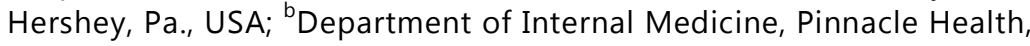 \\ Harrisburg, Pa., USA; ' Department of Gastroenterology and Hepatology, Penn State \\ Milton S. Hershey Medical Center, Hershey, Pa., USA; ${ }^{d}$ Department of Pathology, Penn \\ State Milton S. Hershey Medical Center, Hershey, Pa., USA
}

\section{Keywords}

Crystal deposition $\cdot$ Sevelamer $\cdot$ Cholestyramine $\cdot$ Hematochezia $\cdot$ Ulceration

\begin{abstract}
Lower GI bleeding is a common cause for hospitalization in adults. Medication-associated mucosal injury is an important clinical entity that can result in significant morbidity and mortality. We present the case of a 45-year-old woman with a 3-month history of intermittent abdominal cramping and rectal bleeding. Her medical history was extensive and included end-stage renal disease and a remote history of endometrial carcinoma that was treated with radiation. Initial workup was concerning for ischemic and radiation colitis, however, histology was most consistent with acute inflammation and ulceration associated with crystal fragments. Sevelamer and cholestyramine are commonly used ion-exchange resins that have been associated with mucosal damage. Both medications were discontinued and her symptoms resolved. Our case highlights an underrecognized but important cause of hematochezia.




\section{Introduction}

Lower GI bleeding (LGIB) is defined as hematochezia originating from a site within the colon, rectum, or anus [1]. While most cases of bleeding resolve spontaneously, more severe episodes necessitate hospitalization. The estimated annual incidence of hospitalization is 36 per 100,000, with an even higher rate in the elderly [1]. Mortality rates from colonic bleeding are as high as $2.4-3.9 \%$, with an increased risk in patients $>70$ years and two or more comorbidities $[1,2]$.

Causes of LGIB are categorized by mechanism - anatomic, vascular, inflammatory, and neoplastic. Anatomic causes include diverticulosis and internal hemorrhoids [1]. Vascular causes include ischemia, radiation colitis (or proctitis), and angiodysplasia [1]. Inflammatory bowel disease (e.g. ulcerative colitis and Crohn's disease) and enteroinvasive pathogens can also result in colonic bleeding [1]. Malignancy typically results in occult bleeding. Despite this broad list of differential diagnoses, the most common cause is diverticulosis, accounting for $30-33 \%$ of cases requiring hospitalization [3]. Regardless of the source, LGIB is often complicated by concomitant use of antiplatelet and anticoagulant medications.

Patients with chronic kidney disease have a higher incidence of both upper (UGIB) and LGIB when compared to the general population [4]. Anemia and uremic platelet dysfunction in these patients can exacerbate bleeding and result in significant morbidity and mortality [4]. One study found that peptic ulcer disease was the most common cause of UGIB and angiodysplasia the most common cause of LGIB in chronic dialysis patients [4].

Medication-induced injury of the gastrointestinal tract is common, yet underrecognized [5]. Many drugs have characteristic patterns of injury, while others have an unclear association. For instance, nonsteroidal anti-inflammatory drugs can cause erosion and ulceration in the distal ileum and right-sided colon [5]. Proton pump inhibitors have been associated with microscopic colitis, which is diagnosed by histopathology [5]. Crystal deposition by ionexchange resins (e.g. cholestyramine, sevelamer, and sodium polystyrene sulfonate) may result in mucosal damage, but there have been few reported cases $[5,6]$. We present a case of crystal-associated colitis in a patient with multiple medical comorbidities and intermittent rectal bleeding.

\section{Case Presentation}

A 45-year-old woman presented with a 3-month history of intermittent abdominal cramping and hematochezia. Initially, she noticed occasional bright red blood per rectum when wiping but was otherwise asymptomatic. She had no associated abdominal pain, lightheadedness, chest pain, or shortness of breath. The episodes of rectal bleeding became more frequent and were associated with diffuse abdominal pain, at which point she decided to seek medical attention. Her pertinent medical history includes hemodialysis-dependent endstage renal disease, type 2 diabetes mellitus, ischemic cardiomyopathy, peripheral vascular disease, and endometrial carcinoma that was treated with radiation and surgical resection 22 years previously.

Her first hospitalization was at an outside institution for sepsis secondary to Clostridium difficile colitis. She was found to be anemic and required transfusion of red blood cells. Her abdominal pain and rectal bleeding improved, and she was discharged on oral vancomycin. One month later, she again had repeated episodes of rectal bleeding and abdominal pain. There had been no changes to her medications. She was not on anticoagulation and had not 
Desai et al:: Crystal-Associated Colitis with Ulceration Leading to Hematochezia and Abdominal Pain

been taking any anti-inflammatory medications other than low-dose aspirin. She presented to our tertiary-care hospital for further evaluation.

Upon presentation at our institution, she had normal vital signs with a temperature of $36.0^{\circ} \mathrm{C}$, heart rate of 80 b.p.m., blood pressure of $110 / 50 \mathrm{~mm} \mathrm{Hg}$, respiratory rate of 12 breaths/min, and oxygen saturation of $100 \%$ on 2 liters by nasal cannula. There was no evidence of active gastrointestinal bleeding. She appeared comfortable with normal cardiac and lung exam. Her abdominal exam was significant for mild suprapubic tenderness, otherwise was soft without any guarding, rigidity, or rebound tenderness. Laboratory studies were significant for hemoglobin of $8.0 \mathrm{~g} / \mathrm{dl}$ (range 11.7-15.0) and hematocrit of 25\% (range 3544). Serum lactic acid level was normal. A contrast CT scan of the abdomen showed mesenteric edema without significant colonic thickening. Her medication list was extensive and included baby aspirin, simvastatin, insulin glargine, gabapentin, cholestyramine 4,000 $\mathrm{mg}$ twice daily, and sevelamer 3,200 mg with meals.

She was treated with intravenous fluids and transfusion of one or two units of blood, as needed, with appropriate response. On hemodialysis days, she was noted to have transient, asymptomatic episodes of hypotension with systolic blood pressure ranging from 70 to 80 $\mathrm{mm} \mathrm{Hg}$, raising suspicion for ischemic colitis, although she had bloody bowel movements on nondialysis days as well.

Due to ongoing rectal bleeding, she underwent colonoscopy which showed partially healing linear ulcerations at the flexures, transverse and sigmoid colon, suggestive of ischemic colitis (fig. 1). There was also a stricture approximately $30 \mathrm{~cm}$ from the anal verge that could only be traversed with a pediatric upper scope, revealing inflamed and friable mucosa with neovascularization, consistent with radiation colitis. The working diagnosis was believed to be a combination of ischemic and radiation colitis. Unfortunately, her symptoms persisted despite supportive care.

Two days later, the pathology report for her biopsies returned indicating acute inflammation, ulceration, and granulation tissue associated with fragments of crystal material (fig. 2, fig. 3). After careful review of the patient's medication list and a thorough literature search, both sevelamer and cholestyramine were identified as medications that were associated with the formation of crystal fragments. Both of these medications were immediately discontinued and 2 days later her hematochezia resolved and her hemoglobin level stabilized. She was subsequently discharged to a rehabilitation facility with plans for a repeat colonoscopy in 8 weeks to document mucosal healing; however, the patient died of complications from renal failure 3 weeks prior to the scheduled procedure. No autopsy was performed.

\section{Discussion}

Colitis induced by chemical crystals is underrecognized and can pose a diagnostic challenge. Sevelamer, cholestyramine, and sodium polystyrene sulfonate are all ion-exchange resins that can form crystal fragments and have been associated with mucosal injury [5].

Sevelamer is an anion-exchange resin that binds to dietary phosphate and prevents its absorption from the gastrointestinal tract. Even though it is a commonly prescribed medication for hyperphosphatemia in patients with chronic kidney disease, there have only been a few reported cases of mucosal injury. Swanson et al. [7] reviewed 15 cases of crystal fragments identified on biopsy specimens from four different academic centers. Identification of sevelamer crystal fragments was thought to be an incidental finding in some cases, while in 
others a direct association was suspected given findings of necrosis, ulceration, and crypt distortion [7]. The crystal fragments have been described as having pink linear accents or 'fish scales' that are broad and irregularly spaced with H\&E stain [7].

Cholestyramine is a nonabsorbable ion-exchange resin that is often used to treat hypercholesterolemia and bile salt-induced diarrhea. Crystals associated with this medication have been correlated with erosion, ulceration, and acute inflammation, predominantly in the colon [6]. In comparison to the H\&E preparation of sevelamer crystals, the fragments are typically described as lacking an internal 'fish scale' pattern [7, 8].

Sodium polystyrene sulfonate is commonly used to treat hyperkalemia, especially in patients with renal failure. There have been reported cases of erosive and ulcerative injury to the gastrointestinal tract with sodium polystyrene sulfonate prepared in sorbitol [9]. These fragments have a narrow 'fish scale' pattern and are violet in color with H\&E stain [7].

Our patient had intermittent rectal bleeding and abdominal pain presumably secondary to ischemic colitis given her transient episodes of hypotension during hemodialysis, but histopathology was not consistent with this diagnosis. Biopsy of ischemic colitis typically reveals mucosal necrosis, hyalinization of the lamina propria, and areas of hemorrhage [10]. There were also endoscopic findings consistent with her remote history of pelvic radiation, but histopathology did not support this diagnosis. The appearance of radiation colitis on biopsy shows atypical endothelial cells, fibroblasts, and abnormal blood vessels [10]. The patient's colon biopsies revealed areas of ulceration, inflammation, and granulation tissue with crystalline fragments.

It is difficult to prove whether mucosal crystallization is an innocent bystander phenomenon or the direct etiology of the mucosal injury leading to hematochezia, especially in a patient with multiple chronic medical conditions. Resolution of her symptoms only occurred after discontinuing both sevelamer and cholestyramine, suggesting a causative relationship between these medications and her crystal-induced mucosal injury. While there is literature characterizing the histologic differences between ion-exchange resins, our patient had rectal bleeding requiring blood transfusions; therefore, we stopped any potentially offending medications. In summary, crystal-associated colitis is becoming an increasingly recognized entity in patients taking ion-exchange resins and should be on the differential for causes of LGIB.

\section{Acknowledgements}

We would like to thank Dr. Michael A. Santos for review of the manuscript.

\section{Statement of Ethics}

The authors have no ethical conflicts to disclose.

\section{Disclosure Statement}

The authors have no conflicts of interest to disclose. 


\section{Case Reports in \\ Gastroenterology}

\begin{tabular}{l|l}
\hline Case Rep Gastroenterol 2016;10:332-337 \\
\hline $10.1159 / 000446575$ & $\begin{array}{l}\text { C 2016 The Author(s). Published by S. Karger AG, Basel } \\
\text { www.karger.com/crg }\end{array}$ \\
\hline
\end{tabular}

Desai et al.: Crystal-Associated Colitis with Ulceration Leading to Hematochezia and Abdominal Pain

\section{References}

1 Ghassemi KA, Jensen DM: Lower GI bleeding: epidemiology and management. Curr Gastroenterol Rep 2013;15:333.

2 Strate LL, Ayanian JZ, Kotler G, Syngal S: Risk factors for mortality in lower intestinal bleeding. Clin Gastroenterol Hepatol 2008;6:1004-1010.

-3 Gayer C, Chino A, Lucas C, et al: Acute lower gastrointestinal bleeding in 1,112 patients admitted to an urban emergency medical center. Surgery 2009;146:600-606.

-4 Kalman RS, Marcos PC: Evidence-based review of gastrointestinal bleeding in the chronic kidney disease patient. Semin Dial 2015;28:68-74.

-5 Parfitt JR, Driman DK: Pathological effects of drugs on the gastrointestinal tract: a review. Hum Pathol 2007;38:527-536.

-6 Arnold MA, Swanson BJ, Crowder CD, et al: Colesevelam and colestipol: novel medication resins in the gastrointestinal tract. Am J Surg Pathol 2014;38:1530-1537.

-7 Swanson BJ, Limketkai BN, Liu TC, et al: Sevelamer crystals in the gastrointestinal tract (GIT): a new entity associated with mucosal injury. Am J Surg Pathol 2013;37:1686-1693.

8 Chintamaneni P, Das R, Kuan SF, et al: Hematochezia associated with sevalamer-induced mucosal injury. ACG Case Rep J 2014;1:145-147.

9 Ha C, Kornbluth A: Mucosal healing in inflammatory bowel disease: where do we stand? Curr Gastroenterol Rep 2010;12:471-478.

10 Cerilli LA, Greenson JK: The differential diagnosis of colitis in endoscopic biopsy specimens: a review article. Arch Pathol Lab Med 2012;136:854-864.

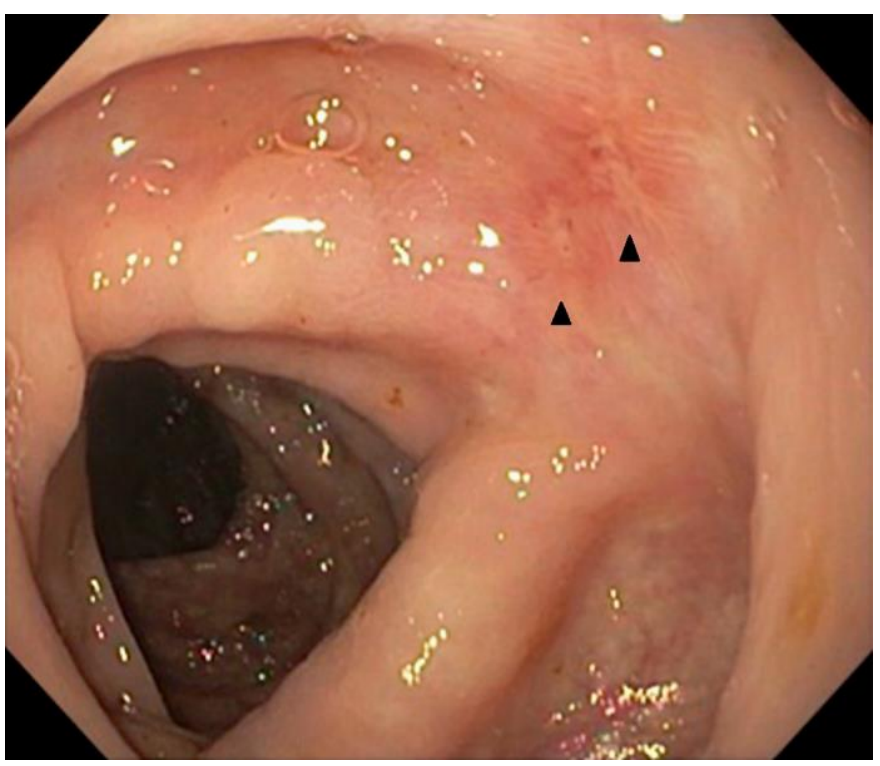

Fig. 1. Linear ulcerations (arrowheads) in the hepatic flexure and descending colon. 


\section{Case Reports in Case Rep Gastroenterol 2016;10:332-337 \\ C 2016 The Author(s). Published by S. Karger AG, Basel Gastroenterology $10.1159 / 000446575$ www.karger.com/crg \\ Desai et al:: Crystal-Associated Colitis with Ulceration Leading to Hematochezia and Abdominal Pain}

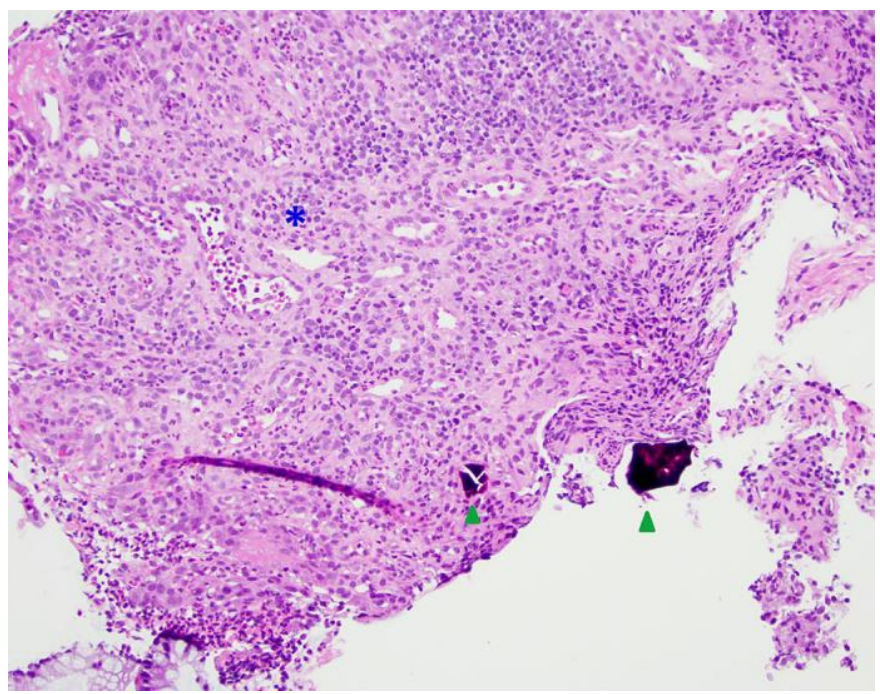

Fig. 2. H\&E stain showing crystal fragments (arrowheads) and ulceration with granulation tissue (asterisk). Original magnification. $\times 200$.

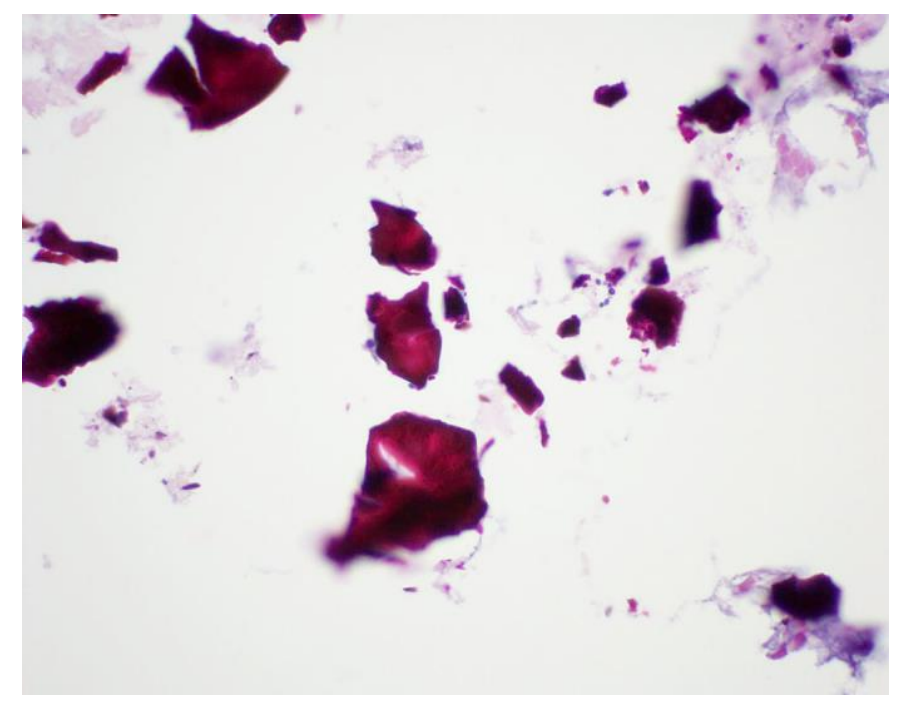

Fig. 3. H\&E stain with a high-power view of the crystal fragments. Original magnification. $\times 600$. 